\title{
DEVELOPMENT OF FUNCTIONALITY-ORIENTED ROBOTIC ENVIRON- MENTS THROUGH PROCESS ANALYSIS AND PROCESS MODIFICATION
}

\author{
Thomas Linner*, Ivana Abazovic, Bernhard Ellmann, and Thomas Bock \\ Chair for Building Realization and Robotics, Technische Universität München, Germany \\ *Corresponding author (thomas.linner@br2.ar.tum.de)
}

\begin{abstract}
For the development of complex AAL-Environments comprising multiple subsystems and assistance technologies new development methods are required exceeding the application scope of architectural methods of space development and methods of barrier-free architecture. In this paper we present the results of a study on the applicability of a product development method which has been based on functional process analysis and individual process modification. The experimental approach was able to generate interesting findings and showed that in environments assisting needy and counterbalancing disabilities a process-oriented organization outperforms the traditional typological organization of living environments.
\end{abstract}

Keywords: Service Robotics, Intelligent Environments, Process Analysis, Integration

\section{INTRODUCTION}

AAL-surroundings are complex life-surroundings which exist of a huge number of intelligent and with microsystem-technology equipped components, prefabricated parts, assemblies, auxiliary technologies and prevention technologies. Up to now a row of new technologies, which can be seen as subsystems for AAL-surroundings and certain application cases, were developed in the course of numerous product developments and research projects. Increasingly there originates the wish to link up these subsystems with each other and to customize single components, for instance through structural and/or infotechnical product adaptation, architectural modular construction systems [1], modular designs and deliberate process development into the surroundings and on different, individual cases of need and those,, Process structures". In this case AAL-surroundings are treated as complex human-machine-interaction systems in which different subsystems are interacting like person (user, relatives, nursing staff, machine, auxiliary supplies and raw materials, services etc.) to support different cases of need. With all these considerations the user and its independency should always be in the center [2] and the AAL-surrounding as an overall system should pursue this goal in optimized way. At the development of complex AAL-surroun-dings which support, e.g., people who suffer from several diseases (multimorbidity) [3], beyond the pure physical level - which can be covered by architecture-close methods of space creation or by barrier-free construction - numerous other influencing variables appear (technology/hardware, software, demand of services, Fig. 1), which interfere with the behavior and the processes of the overall system.

\begin{tabular}{|c|c|c|c|c|}
\hline Level & Physical & Tochnology & Software & Service \\
\hline Sub-Systems & $\begin{array}{l}\text { Structure } \\
\text { Facade } \\
\text { Walls } \\
\text { Windows } \\
\text { Cables } \\
\text { Pipes } \\
-\end{array}$ & $\begin{array}{l}\text { Appliances } \\
\text { Electronics } \\
\text { Sensors } \\
\text { Actors } \\
-\end{array}$ & $\begin{array}{l}\text { Distributed C. } \\
\text { Applications } \\
\text { nitillgence } \\
\text { Serf Learning } \\
\text { Proectivity } \\
-\end{array}$ & $\begin{array}{l}\text { Supply } \\
\text { information } \\
\text { Health } \\
\text { Care } \\
\text { Libe Style } \\
\text { Rearrangement } \\
\text { Maintenance } \\
\text { Energy } \\
\text { - }\end{array}$ \\
\hline
\end{tabular}

Fig. 1 Sub-categories in complex AAL-environments, consisting of a variety of subsystems [2].

The integration of new AAL-subsystems which extend the physical level by functionalities from the areas of technology/hardware, software and services can be effected by: 


\begin{abstract}
a) Flexibility and Adaptivity
An intelligent surrounding is of benefit not only for older or physically weaker/challenged people, but also for the younger and stronger, because it prevents long ways, allows efficient process expiries and also simply offers a certain comfort. By a modular construction the apartment can adapt itself always anew to familiar and/or physical changes of his/her inhabitant/s. [4].
\end{abstract}

b) Integration of Subsystems by Design

In consideration of the especially in Europe still rather skeptical mindset to new and assistive technologies is clear that a demanding design in connection with a good marketing concept is very important [5]. Technology should step in the background and only be visible in use.

\section{c) Optimization of Processes}

To create process-optimized residential surrounding, only the architectural construction itself is not sufficient. Rather it is a matter of an interconnected overall system which distributes the complexity to several subsystems (information technology, micro-systemtechnology, mechatronics, geronto technology, relatives, nursing staff etc.). A functional core contains bath- and culinary elements and offers storage space and short ways [6]. This central element is linked with all pieces of furniture in the apartment and contains, in addition, communication (video telephony, internet order, e-mail, etc.), house security and - in case of need - telemedical elements. Through the interconnection of the pieces of furniture objects, which are lost, can be found, or drinks / food can be automatically transported to the table, to mention only some examples.

Subjects as flexibility and adaptivity for integration of subsystems by architecture/design were already given attention to in the present research projects. The analysis and optimization of processes in the domestic AALsurroundings, which consist of a huge number of subsystems of different categories to support certain case of need, is a new aspect, which up to now was barely taken into account. Therefore, in this contribution this aspect is dealt with in detail.

\section{PROCESS ANALYSIS}

With the development and integration of new AALsystems into the residential surrounding complex overall systems are built, which have a direct and active interaction with the inhabitant. Methods of architecture concern- ing the organization of rooms and functions just as the recommendations from the area of barrier-free construction are not sufficient to control this new complexity. Methods of analysis and reorganization of complex human-machine-interaction systems are also not a new invention. The following examples show proven attempts.

\subsection{Taylor and Ford}

Frederick W. Taylor worked on the scientific penetration of working processes. By the consideration of the processes of working surroundings and of in connection with certain persons and tools standing processes (process analysis), their regulation and following reorganization (process education) after one,, Best Way“ [7] principle became achievable. Taylor observed not only the single factors, but was also interested especially in the consequences of the single factors and their combination with each other, thus on the overall system. This can be seen very well at the example of the slide rule for shooting, which Taylor had developed to be able to determine the consequences of different influencing variables on a process unit. Like Taylor Ford also observed the overall system and saw the people as an integral sub-unit of this system [8]. Taylor and Ford determined not only work routines or mechanical, technical processes, but their goal was rather to understand the complex interaction of human, machine, time, auxiliary supplies and raw materials to be able to achieve process improvements by their reorganization. With this they also created the basis for the specific new development of socio-technical systems or of systems, in which human and machine interoperate synergetic.

\subsection{Fusion of Human and Machine}

Today complex human-machine-interaction systems apply increasingly in the individual production of products by adaptable manufacturing systems. Possibilities of technical systems are united with the flexibility and combination ability of people. Surrounding, person, expiry, tool, raw materials are adapted for each other so that a trouble-free and highly efficient overall system is created.

The complexity of the whole assignment is distributed to 
all subsystems.

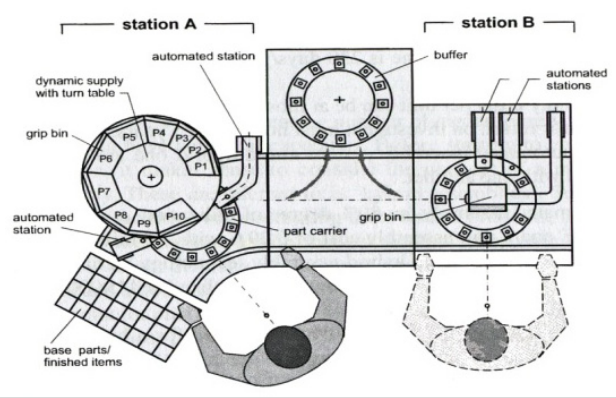

Fig. 2 Coupling of the possibilities of technical systems (Speed, power, precision) with human skills in the industrial production of individual products. [9]

\subsection{Processes in Residential Spaces}

The "Frankfurter Küche", in which the order and the form of single elements as well as the planned interaction have arisen from the analysis of the processes, can be taken as an example for specific process improvement in the residential sphere. In comparison to a conventional kitchen of this time it is very well recognizable that in the "Frankfurter Küche" the ways and amount of work involved have become shorter, because the process expiries were taken into account.
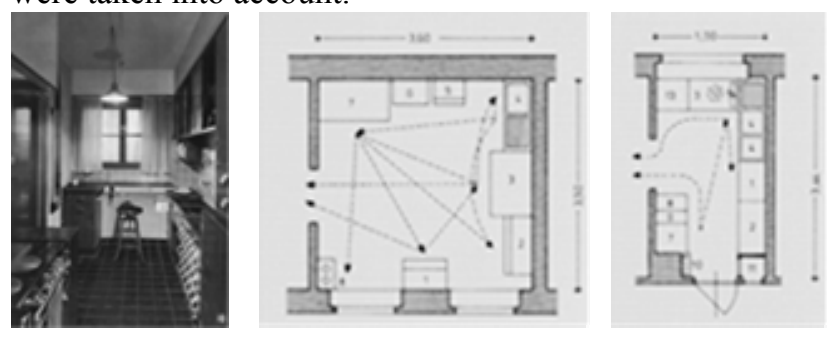

Figs. 3 „Frankfurter Küche“. Left: Functional kitchen, interior view.

Middle: Kitchen without optimized functionality. Right: „Frankfurter

Küche“. [11]

\section{PROCESS DESIGN}

The demonstrated and by the development of complex socio-technical systems successfully applied process-like perception can also provide important starting points by the development of complex AAL-surroundings or the implementation of single AAL-components. For the determination of basic processes, which can be assigned to the different AAL-surrounding configurations, a scenario technology is used at the beginning. After that optimized functional and technical requirements as well as the accompanying processes are evaluated and defined anew. As the process-like perception has pointed out here, the functional assignment of subsystems in the residential surrounding becomes more important than the classical separation and assignment of the subsystems to the known space types (bath, kitchen, living, sleeping, hall, work etc.) with the increase of assistance- and nursingdemand.

\subsection{Scenarios}

Scenarios of utilization give examples of possible use of the system under certain circumstances. They give an important input for design and system construction, represent „Usability engineering“ in a very early project phase and support the definition and optimization of processes.

\subsubsection{Single without Assistance Demand}

Ms. Schneider is 28 years old, lives alone and works 60 70 hours a week. She has no physical or mental issues. Hence she wants to spend as little time as possible with housekeeping or purchasing. In the morning she gets up around $6.30 \mathrm{~h}$, goes into the bathroom and changes afterwards. Then she still has got half an hour for a quick breakfast and the coffee. She puts the breakfast dishes into the dishwasher, orders cheese in an online store, because her fridge signals that this shelf is empty, and finally goes to the work. Around 20.30 she gets back home again and her apartment manager tells her that the cheese was delivered and that two friends left her a video message, which is projected onto the culinary wall while she starts preparing the dinner. At the same time the sensor-steered vacuum cleaner goes through the apartment, because she expects her boyfriend to come over for dinner. Before he gets over, she goes into the shower quickly in order to freshen up. Afterwards she folds the sanitary objects away again and activates the automatic cleaning program, while her boyfriend stands in front of the door already, which is shown to her on a screen, because she has got a camera integrated into the door.

\subsubsection{Family with Children}

Mrs. Schneider is 35 years old now, has married and is 
the mother of Elias (5) and Charlotte (1). She works parttime at home, while her husband is employed full-time. Since she has to coordinate family and work, she still is grateful for the help of her apartment manager. However, she added some useful features by now. In a family with little children there is a big amount of dirty laundry, which is why she has got different integrated fields for cooking-, color- and sensitive-washing programs, which are sliding automatically into the washing machine once the drawer is full. Also she has got an attachment with which she can transform the sink into a diaper-changing table for Charlotte. Because Charlotte was a premature child and has got a heart suffering, her vital parameters are saved by a bracelet at night and are passed on directly to the communication center of the apartment, which sends a signal to the parents and Charlottes pediatrician when required. In addition, the family has installed height-adjustable sanitary objects, so that Elias can reach the sink and can also go to the toilet independently. Through the big amount of supporting devices for the household, which are integrated into the apartment manager, Mrs. Schneider can coordinate family and working life much better.

\subsubsection{Family without Children}

Mrs. Schneider is 55 years old and the children have already moved out. Since she is alone with her husband now, distant-medical devices are removed and also the laundry sorter is not necessary anymore. They are keeping the height-adjustable sanitary objects, because the mother of Mrs. Schneider is visiting them frequently and she is not as mobile as she was 10 years ago. Mrs. Schneider and her husband are both working full-time again, which is why they still use online services for purchasing and why they are still grateful for the automatic cleaning of culinary- and bath-equipment. Also they are travelling more often now, because the children moved out so they have more time for each other. While they are travelling, the sensor-steered alarm system in their apartment gives them a feeling of safety.

\subsubsection{Single with Assistance Demand}

Now Mrs. Schneider is 78 years old and has lost her husband due to a sailing accident. She slowly becomes forgetful and is not very mobile anymore. Hence, she installed the distant-medical devices again. Her vital parameters are measured by a bracelet and passed on to the communication center of her apartment manager. Since she does not want to go out that often any more, she gets doctor's appointment via video conferences and can also keep in touch with her children and grandchildren (they cannot see each other that often anymore because they live in different cities by now) via this video conference system. Her bathtub was exchanged for a shower without thresholds so that she does not on the help of other people for getting in or out. She still receives her purchasing and medication from the online service company, additionally she installed automatic turn off mechanisms for kitchen and lighting, in case that she forgets to switch off the light or stove top some time before she leaves the apartment.

\subsection{Processes and Requirements}

The process-matrices 1 to 4 arise from the evaluation of these scenarios. All relevant processes are summarized into seven categories - hygiene, ingestion, services, videotelephony, distant medicine, house security and cleaning- and are further divided as per margin. In the graphics referring to the different user groups it can be read with the registered figures and letters whether or not the single processes belong to the everyday life of the user group and which modifications are necessary for optimizing the assistance in case of need (cf scenarios 1-4). One can also read the useful subsystems (methods, technologies, services let themselves etc.). Thus it can for instance with logical linking be read from matrix 3, that user group 1 needs no distant medicine devices and from matrix 4 (Single without assistance demand) that it is sensible for user group 2 (family with children) to integrate a height-adjustable toilet to fulfill the different ergonomic requirements. The probably most interesting and for the future creation of AAL-surroundings probably also the most important knowledge from the analysis by means of process-matrices is the statement, that from this perception the assignment of the processes, features, 
sub-systems and technologies to classical room types like kitchen, bath, living, work etc. is immaterial. Importantly to the fulfillment of certain assistance assignments is the optimal combination of the available resources to efficient processes. Within AAL classical room assignments are questioned by this approach concerning her usability. As the listing of the process-matrices for the scenarios has pointed out here, the functional assignment of subsystems in the residential surrounding for the education of optimal processes becomes the determining criterion with the increase of assistance- and nursing-demand. This seems to be more important than the classical separation and assignment of the subsystems to the known room types (bath, kitchen, living, sleeping, hall, work etc.).
1) Hygiene
A) toilet
B) teeth cleaning
C) taking a shower
D) changing
E) sorting and storing dirty laundry
F) cleaning of clothes
G) storage for clothes
H) storage for cosmetics
2) Ingestion
A) cutting / preparing
B) cooking
C) baking
D) cleaning dishes
E) storing dishes
F) food storage cooled
G) food storage uncooled

$\begin{array}{ll}\text { 3) Services } & \text { A) display whether food or cosme-tics or medi- } \\ \text { cation are missing } \\ \text { B) automatic order and delivery } \\ \text { 4)Video } \quad \text { Te- } & \text { A) phone calls incoming } \\ \text { lephony } & \text { B) phone calls outgoing } \\ \text { C) conferences } \\ \text { D) message acceptance } \\ \text { 5)Distant } & \text { E) message dispatch } \\ \text { Medicine } & \text { B) measuring of vital parameters } \\ & \text { C) storage and dispatch of the parameters }\end{array}$

feature)

$\begin{array}{ll}\text { 6)House Secu- } & \text { A) alarm system } \\ \text { rity } & \text { B) report of arriving visitors } \\ & \text { C) recording the current location of the inhabi- } \\ & \text { tant }\end{array}$

\section{7) Cleaning of all surfaces and Machines}

Matrix 1-4, Abbreviations:

W (water), AW (sewage), pages (electricity), I (Internet), X stands for necessary, $\mathrm{O}$ stands for not necessary, $\mathrm{X} / \mathrm{O}$ for optional:

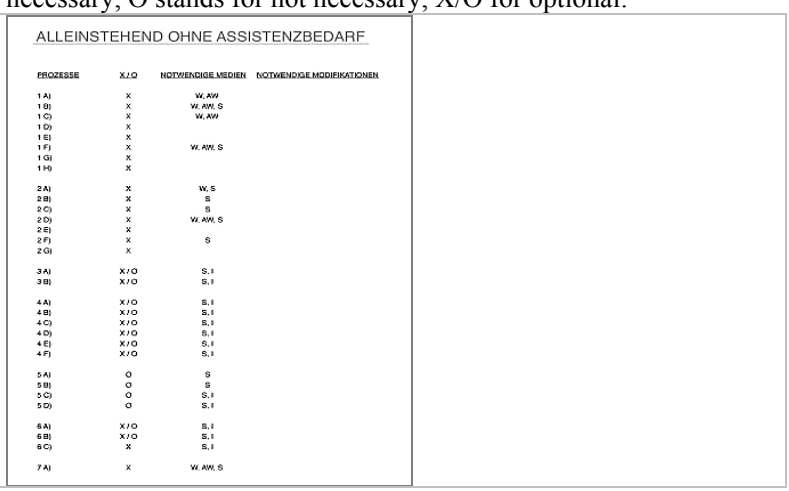

Matrix 1 Requirements User Group 1

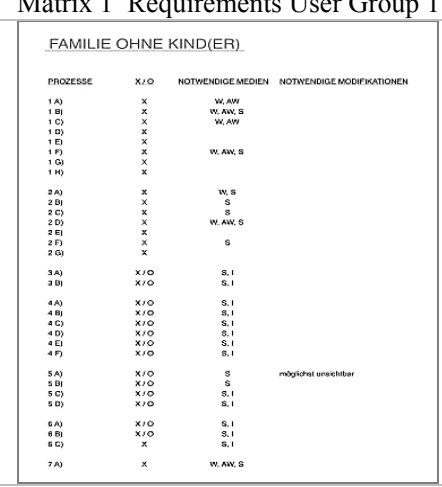

Matrix 2 Requirements User Group 3

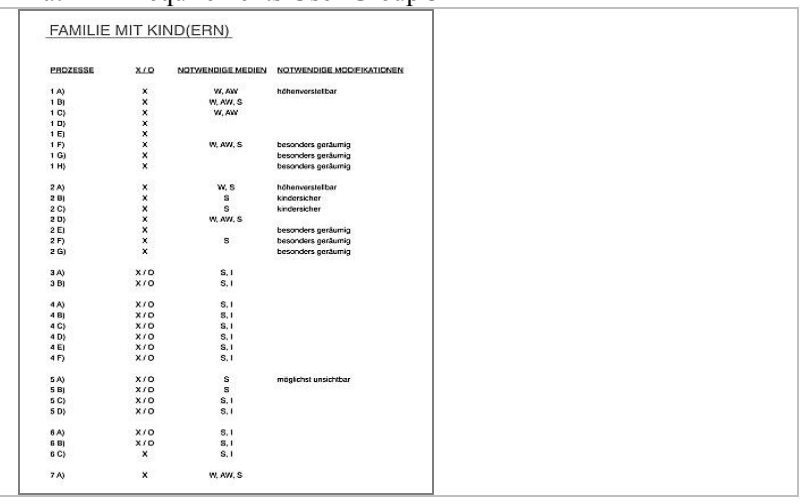

Matrix 3 Requirements User Group 2 


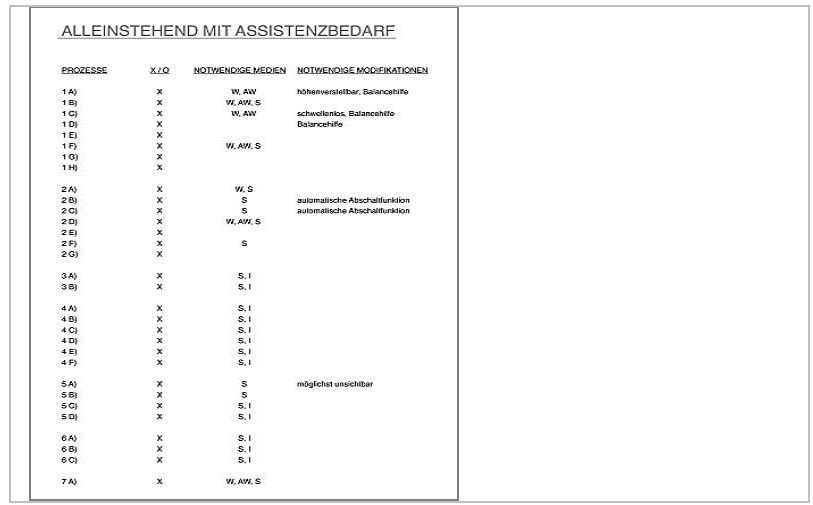

Matrix 4 Requirements User Group 4

\section{PROCESS OPTIMIZATION}

As established in chapter 3, the classical subdivision of the apartment into living areas should be nullified in order to optimize the order of the features in complex AAL-surroundings and to support specific cases of need. This would entail that subsystems could be arranged freely and, if necessary, even dynamically over time, so that a certain combination restrictions or diseases (multimorbidity) by a certain set of involved parties and subsystems can be compensated optimally. To specify this abstract thesis, an exemplary residential surrounding was developed virtually (with the aid of 3D CAD systems) and simulated, which fulfills the appealed criteria (Fig. 4). A compact residential wall is the center of this solution possibility, which contains or/and controls all essential features and AAL-technologies. Details are described in [8]. The residential wall itself is constructed modular so that it can be equipped with features and technologies individually and according to the residential surrounding. At the same time the residential wall functions as a central core of the apartment, around which the remaining residential features can be organized freely, dynamically and without restriction by partition walls. Just like with the "Frankfurter Küche" run ways, working processes and strains can be optimized by optimized configurations on the one hand. On the other hand, the AAL-subsystems can be arranged to allow an interaction among them by trouble-free processes and a planned human-machineinteraction. To be able to achieve this process improvement, the feature organization should take place in differ- ent zones, graded around the central residential wall core (Fig. 6).

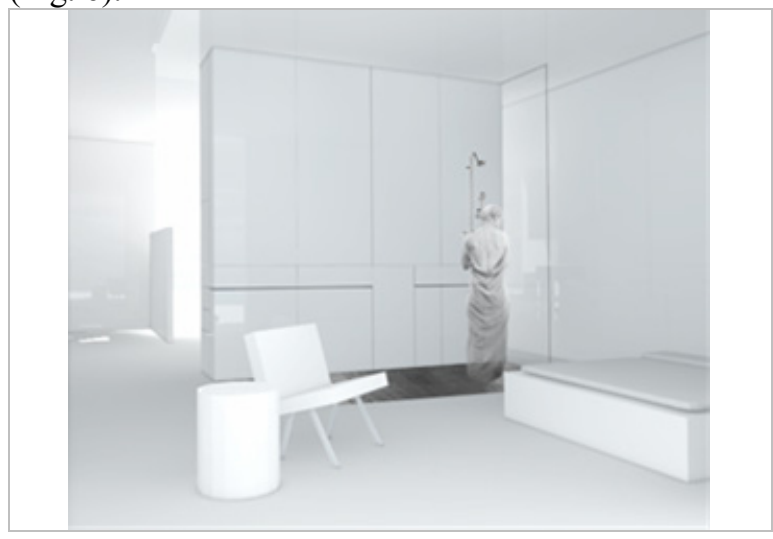

Fig. 4 Simulation of a compact wall unit. It contains and controls all essential functions

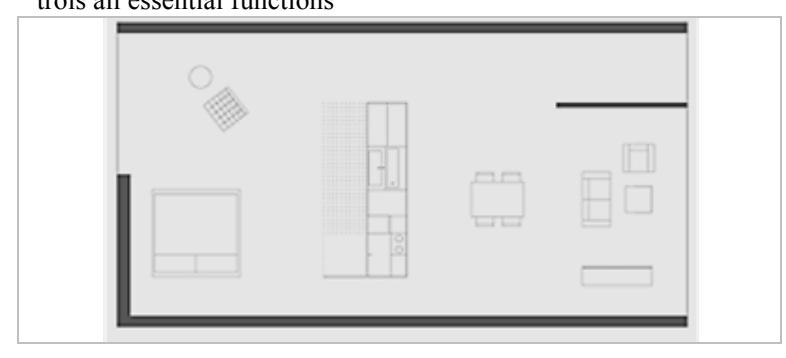

Fig. 5 Wall unit as the center of the apartment.

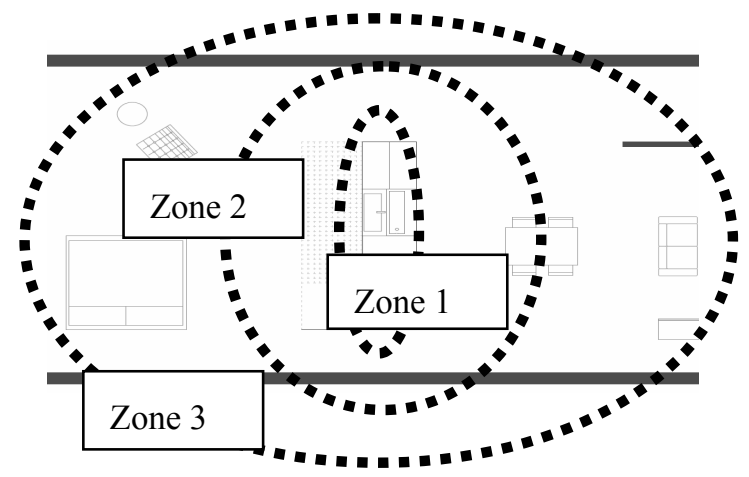

Fig. 6 Zoning replaces traditional division of closed living spaces and allows process-oriented optimization inside the home. Zone 1: Installations and Household Equipment; Zone 2: Hygiene, Food, Homework; Zone 3: Living, Sleeping.

\section{CONCLUSION}

It became apparent that AAL-surroundings are complex life surroundings, which exist of a huge number of intelligent and with micro system technology equipped components, units, assemblies, auxiliary- and prevention technologies. To optimize such complex residential sur- 
roundings for certain assistance cases and cases of need, the methods of architecture for the organization of rooms and features just as the recommendations from the barrier-free construction alone are not sufficient. On the basis of examples from other industry areas and fields of scientific research it was shown how processes in sociotechnical systems are analyzed and optimized. For the investigation of the applicability of a development method orientated towards processes, scenarios of use were created and analyzed and optimized concerning their process peculiarities. With this first experimental approach it was shown that with the increase of assistanceand nursing demand the functional assignment of subsystems in the residential surrounding for the creation of optimal processes becomes the determining criterion. This seems to be more important here than the classical separation and assignment of the subsystems into the known room types. A zoning around a central, functional-compact AAL-residential core could replace the classical separation in closed residential rooms in future and it could allow an optimization oriented towards processes within the AAL-apartment. The criteria worked out in this contribution were already taken into consideration during the development of a functioning, experimental prototype of a modular residential wall / of a modular residential core (zone 1) in the graduation 1:4 (Fig. 7). In the next step the overall system is tested in a real residential sphere and is developed further.

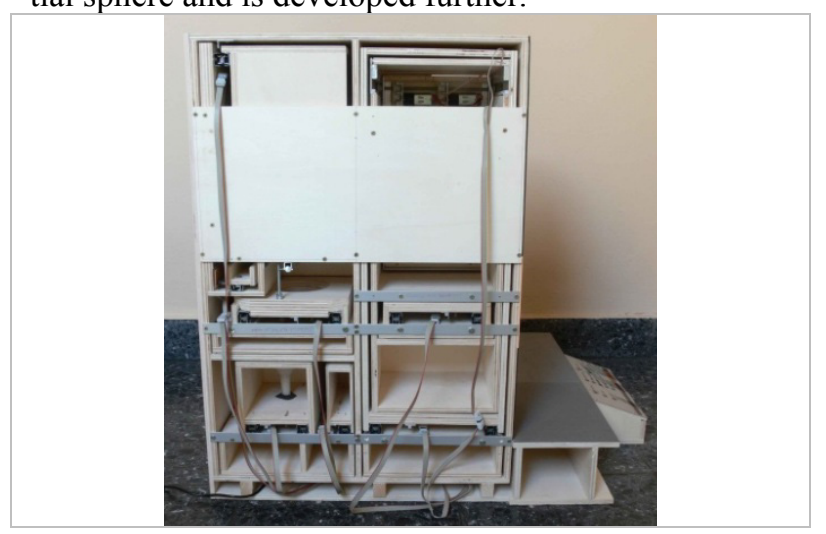

Fig. 7 Functioning prototype of a modular residential wall / of a modular residential core (zone 1) in graduation 1:4.

\section{REFERENCES}

[1] Bock, T.; Linner, T., "Service Oriented Design", 2nd Ambient
Assisted Living Congress, Berlin, 2009.

[2] Bock, T.; Linner, T., "Mass Customization und plattformbasierte, adaptive Baukastensysteme für Ambient Assisted Living-Umgebungen”, 3rd Ambient Assisted Living Congress, Berlin, 2010.

[3] Ford, H. (1926). Today and Tomorrow. Commemorative Edition, 1926, updated June 1988.

[4] Ford factory, first moving assembly line, 1913, Highland Avenue, Detroit. 1913 American Landscape and Architectural Design, 18501920, F. Loeb Library, Graduate School of Design,

[5] Hebeisen, W. (1996). F. W. Taylor und der Taylorismus: über das Wirken und die Lehre Taylors und die Kritik am Taylorismus. Zürich: vdf, 1999, p. 52.

[6] Huber, A., „Neues Wohnen in der zweiten Lebenshälfte“

[7] Linner, T., Bock, T., "Smart Customization in Architecture: towards customizable intelligent Buildings", Conference on Mass Customization, Personalization and Co-creation, Helsinki, 2009.

[8] Linner, T., Kranz, M., Roalter, L., Bock, T., “Compacted and Industrially Customizable Ambient Intelligent Service Units: Typology, Examples and Performance", The 6th International Conference on Intelligent Environments, Kuala Lumpur, Malaysia, 2010.

[9] Lotter, B.; Wienedahl H-P., "Changeable and Reconfigurable Manufacturing Systems", Changeable and Reconfigurable Manufacturing Systems, editor hoda A. ElMaraghy, pp. 127- 176, 2009.

[10] Meyer, S., „Der Nutzer im Zentrum: Anforderungen, Wünsche, Erfahrungen“, 2nd Deutscher AAL-Kongress, Berlin, 2009.

[11] Schütte-Lihotzky, M., „Die Frankfurter Küche von Margarete Schütte-Lihotzky“, Berlin, 1992.

[12] Steffen, G.;Fritz, A., „Wohnen mit Assistenz“, Bauforschung für die Praxis. Band 78. Gabriele Steffen, Antje Fritz, Weeber + Partner,

[13] Van den Acker, M.; Buntinx, F.; Metsemakers, J.F.; Roos, S.; Knottnerus, J.A., "Multimorbidity in general practice: prevalence, incidence, and deter-minants of co-occurring chronic and recurrent diseases", Pub Med J. Clin Epidemiol, pp. 367-375, 1998.

[14] Master Course "Advanced Construction and Building Technology", www.br2.ar.tum.de - T. Bock, T. Linner 